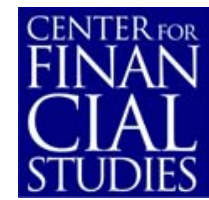

No. $2005 / 16$

Discretionary Monetary Policy and the Zero Lower Bound on Nominal Interest Rates

Klaus Adam and Roberto Billi 


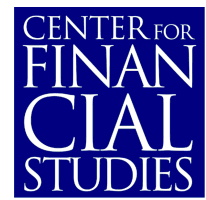

\section{Center for Financial Studies}

The Center for Financial Studies is a nonprofit research organization, supported by an association of more than 120 banks, insurance companies, industrial corporations and public institutions. Established in 1968 and closely affiliated with the University of Frankfurt, it provides a strong link between the financial community and academia.

The CFS Working Paper Series presents the result of scientific research on selected topics in the field of money, banking and finance. The authors were either participants in the Center's Research Fellow Program or members of one of the Center's Research Projects.

If you would like to know more about the Center for Financial Studies, please let us know of your interest.

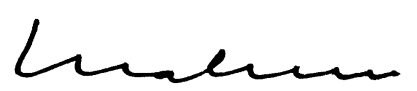

Prof. Dr. Jan Pieter Krahnen

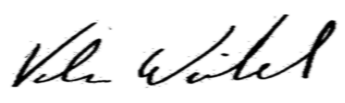

Prof. Volker Wieland, Ph.D. 
CFS Working Paper No. 2005/16

\title{
Discretionary Monetary Policy and the Zero Lower Bound on Nominal Interest Rates*
}

\author{
Klaus Adam ${ }^{1}$ and Roberto Billi ${ }^{2}$ \\ First Version: October 3, 2003 \\ Current Version: March 14, 2005
}

\begin{abstract}
:
Ignoring the existence of the zero lower bound on nominal interest rates one considerably understates the value of monetary commitment in New Keynesian models. A stochastic forward-looking model with lower bound, calibrated to the U.S. economy, suggests that low values for the natural rate of interest lead to sizeable output losses and deflation under discretionary monetary policy. The fall in output and deflation are much larger than in the case with policy commitment and do not show up at all if the model abstracts from the existence of the lower bound. The welfare losses of discretionary policy increase even further when inflation is partly determined by lagged inflation in the Phillips curve. These results emerge because private sector expectations and the discretionary policy response to these expectations reinforce each other and cause the lower bound to be reached much earlier than under commitment.
\end{abstract}

JEL Classification: E31, E52

Keywords: Nonlinear Optimal Policy, Occasionally Binding Constraint, Sequential Policy, Markov Perfect Equilibrium, Liquidity Trap

\footnotetext{
* We would like to thank an anonymous referee who provided helpful comments and suggestions. Errors remain ours. The views expressed reflect the authors' own opinions and not necessarily those of the European Central Bank.

${ }^{1}$ Corresponding author: CEPR, London and European Central Bank, Kaiserstr. 29, 60311 Frankfurt, Germany, email: klaus.adam@ecb.int

${ }^{2}$ Center for Financial Studies, Taunusanlage 6, 60329 Frankfurt, Germany, email: billi@ifk-cfs.de
} 


\section{Introduction}

The relevance of the zero lower bound on nominal interest rates for the conduct of monetary policy is a much debated issue among both policymakers and academics. Clearly, the economic experience of Japan during the last decade as well as the low levels of nominal interest rates prevailing in Europe and the United States contribute to the renewed interest in this topic. ${ }^{1}$ Although deflationary pressures seem eventually to be subsiding, investigating this issue remains relevant for effectively dealing with such pressures should they reemerge.

Surprisingly, however, a systematic investigation of the policy implications arising from the lower bound in stochastic models with forward-looking agents is not available yet. This paper determines discretionary monetary policy in a benchmark New Keynesian model, featuring monopolistic competition and sticky prices in the product market (see Clarida, Galí and Gertler (1999) and Woodford (2003)), under standard conditions of uncertainty and taking explicitly into account the existence of the lower bound.

Studying a fully stochastic setup with lower bound is of interest because it allows us to calibrate the model, to the U.S. economy, and study the welfare implications of discretionary monetary policy. In particular, comparing our results to those obtained under commitment in Adam and Billi (2004), we illustrate that ignoring the existence of the lower bound one may significantly understate the value of policy commitment.

Analyzing a purely forward-looking model, we show that under discretionary monetary policy a fall in the natural real rate of interest generates large output losses and a sizable amount of deflation. ${ }^{2}$ In particular, for our benchmark calibration a negative three standard deviation value of the natural real rate leads to an output gap of about $-8 \%$ and an annual rate of inflation around

\footnotetext{
${ }^{1}$ For recent discussions see Auerbach and Obstfeld (2003), Coenen and Wieland (2003), Eggertsson and Woodford (2003), and Svensson (2003).

${ }^{2}$ The 'natural' real rate of interest is the real interest rate that renders the allocation in the sticky price economy identical to the efficient allocation.
} 
$-1.8 \%{ }^{3}$ The fall in both output and inflation is found to be considerably larger than in the case with policy commitment and does not show up at all if the model ignores the existence of the lower bound. In fact, under commitment output falls by less than $2 \%$ and inflation by less than $0.1 \%$.

As a result, the unconditional welfare losses generated by discretionary policy increase markedly if the model takes into account the lower bound. For our benchmark calibration the welfare equivalent consumption losses generated by discretionary policy increase by about $65 \%$. However, we find that depending on the precise parameterization of the model the consumption losses may easily increase by as much as $300 \%$. The consumption losses generated by discretionary policy increase even further if we depart from our fully forward-looking specification, allowing inflation to be partly determined by lagged inflation in the Phillips curve (see Billi (2004) for the case with policy commitment).

Overall, these results emerge because in a fully stochastic setup private sector expectations of future output and inflation and the discretionary policy response to these expectations reinforce each other, causing the lower bound to be reached much more often than under commitment. Compared to the case with commitment, the private sector expects larger output losses and stronger deflation once the lower bound is reached: discretionary policy cannot engage in credible promises about the conduct of future policy actions, therefore, it is unable to lower real interest rates by promising future inflation. ${ }^{4}$ Since adverse shocks may always cause the lower bound to be reached in the future, private agents expect lower output and inflation even at times when nominal rates are still positive. Reduced inflationary expectations increase real interest rates and put downward pressure on actual output and inflation. This induces policy to lower nominal rates, which causes the lower bound to be reached much earlier than under commitment. This in turn justifies even lower expectations of future output and inflation and generates additional downward pressure on the actual

\footnotetext{
${ }^{3}$ The natural real rate then temporarily stands at $-1.39 \%$.

${ }^{4}$ Any monetary expansion implemented during a time of zero nominal rates is expected to be reversed once the lower bound ceases to be binding, see Eggertsson and Woodford (2003).
} 
values of these variables.

The literature on monetary policy under discretion was initiated by the seminal contributions of Kydland and Prescott (1977) and Barro and Gordon (1983). More recently, it has been extended to fully micro-founded models in Clarida et al. (1999) and Woodford (2003). ${ }^{5}$ The relevance of the zero lower bound under discretionary policy was first noted by Krugman (1998) who emphasized that the credibility problem may generate a deflation problem. Eggertsson (2005) and Jeanne and Svensson (2004) build upon this idea and discuss potential solutions to the credibility problem.

The remainder of this paper is structured as follows. Section 2 introduces the economic model and section 3 explains how we solve it. After presenting the calibration to the U.S. economy in section 4, we illustrate the welfare implications of discretionary policy in section 5. To explain the welfare results, first we analytically determine the perfect foresight equilibrium in Section 6 , then we present detailed results for the stochastic equilibrium in Section 7. Section 8 checks the robustness of our findings with respect to the model specification and parameterization. Section 9 briefly concludes. Analytical derivations and our numerical algorithms are described in the appendix.

\section{The Model}

We consider a well-known monetary policy model of a representative consumer and firms in monopolistic competition facing restrictions on the frequency of price adjustments (Calvo (1983)). Following Rotemberg (1987), this is often referred to as the 'New Keynesian' model, that has frequently been studied in the literature, e.g., Clarida, Galí and Gertler (1999) and Woodford (2003).

We augment this otherwise standard monetary policy model by explicitly imposing the zero lower bound on nominal interest rates. We thus consider the

\footnotetext{
${ }^{5}$ Albanesi et al. (2003), and King and Wolman (2003) highlight that when monetary authorities act under discretion multiple steady states may arise.
} 
following problem:

$$
\begin{aligned}
& \max _{\left\{y_{t}, \pi_{t}, i_{t}\right\}}-E_{t} \sum_{i=0}^{\infty} \beta^{i}\left(\pi_{t+i}^{2}+\lambda y_{t+i}^{2}\right) \\
& \text { s.t. } \\
& \pi_{t}=\beta E_{t} \pi_{t+1}+\kappa y_{t}+u_{t} \\
& y_{t}=E_{t} y_{t+1}-\sigma\left(i_{t}-E_{t} \pi_{t+1}\right)+g_{t} \\
& i_{t} \geq-r^{*} \\
& u_{t}=\rho_{u} u_{t-1}+\varepsilon_{u, t} \\
& g_{t}=\rho_{g} g_{t-1}+\varepsilon_{g, t} \\
& u_{t}, g_{t} \text { given } \\
& \left\{y_{t+i}, \pi_{t+i}, i_{t+i}\right\} \text { given for } i \geq 1
\end{aligned}
$$

where $\pi_{t}$ denotes the inflation rate, $y_{t}$ the output gap, and $i_{t}$ the nominal interest rate expressed as deviation from the interest rate consistent with the zero inflation steady state.

Under certain conditions the monetary policy objective (1) can be interpreted as a quadratic approximation to the utility of the representative household. ${ }^{6}$ The welfare weight $\lambda>0$ is then given by

$$
\lambda=\frac{\kappa}{\theta}
$$

where $\theta>1$ denotes the price elasticity of demand for the goods produced by monopolistic firms. Equation (2) is a forward-looking Phillips curve summarizing, up to first order, profit-maximizing price setting behavior by firms, where $\beta \in(0,1)$ denotes the discount factor and $\kappa>0$ is given by

$$
\kappa=\frac{(1-\alpha)(1-\alpha \beta)}{\alpha} \frac{\sigma^{-1}+\omega}{1+\omega \theta}
$$

\footnotetext{
${ }^{6}$ This requires steady output to be efficient, e.g., thanks to the existence of an output subsidy that neutralizes the distortions from monopolistic competition, and the output gap to be defined as the difference between the actual output level and the efficient level, see chapter 6 of Woodford (2003) for details.
} 
with $\alpha \in(0,1)$ denoting the share of firms that cannot adjust prices in a given period, $\sigma>0$ the household's intertemporal elasticity of substitution, and $\omega>0$ the elasticity of a firm's real marginal costs with respect to its own output level. ${ }^{7}$ Equation (3) is a linearized Euler equation summarizing, up to first order, households' intertemporal maximization. The shock $g_{t}$ captures the variation in the 'natural' real interest rate and is usually referred to as a real rate shock, i.e.,

$$
g_{t}=\sigma\left(r_{t}-r^{*}\right)
$$

where the natural real rate $r_{t}$ is the real interest rate consistent with the flexible price equilibrium, and $r^{*}=1 / \beta-1$ is the real rate of the deterministic zero inflation steady state. ${ }^{8}$ The requirement that nominal interest rates have to remain positive is captured by constraint (4). Finally, equations (5) and (6) describe the evolution of the shocks, where $\rho_{j} \in(-1,1)$ and $\varepsilon_{j, t} \sim i i N\left(0, \sigma_{j}^{2}\right)$ for $j=u, g{ }^{9}$

Assuming the monetary policymaker cannot commit to future plans, one solves problem (1)-(8) on a period-by-period basis. In other terms, the policymaker rationally anticipates its inability to commit, therefore, treats future values of $y, \pi$ and $i$ as given. This is captured by constraint (8). This is the only point of departure from the case with policy commitment, where the entire solution is determined in period zero, see Adam and Billi (2004).

One should note that (1)-(8) describes a social planning problem since in addition to the nominal interest rate the policymaker also 'chooses' the preferred output level and inflation rate. We thus implicitly allow the policymaker to select the preferred equilibrium outcome consistent with discretionary monetary policymaking. In this paper we do not discuss how policy can insure that the

\footnotetext{
${ }^{7}$ See chapter 3 in Woodford (2003) for further details.

${ }^{8}$ The shock $g_{t}$ summarizes all shocks that under flexible prices generate time variation in the real interest rate, therefore, it captures the combined effects of preference shocks, productivity shocks, and exogenous changes in government expenditure.

${ }^{9}$ As shown in Adam and Billi (2004), this specification of the shock processes is sufficiently general to describe the historical sequence of shocks in the U.S. economy for the period 1983:12002:4 that we consider.
} 
preferred outcome is indeed the only one consistent with the way interest rate policy is conducted. This is a matter of policy implementation, which is beyond the scope of this paper; the reader may want to refer to Giannoni and Woodford (2003) for a treatment in the linear case.

\subsection{Discussion}

\subsubsection{Relation to earlier work}

The new feature of the discretionary maximization problem introduced in the previous section is the presence of both the zero lower bound (4) and the stochastic disturbances $\varepsilon_{u, t}$ and $\varepsilon_{g, t}$. These elements together render the policy problem nonlinear, since the disturbances will cause the nominal interest rate to occasionally reach the lower bound.

The model without lower bound is analyzed in Clarida, Galí and Gertler (1999). Without lower bound the policy problem is linear quadratic, so one can solve for the equilibrium dynamics analytically using standard methods. Jung, Teranishi, and Watanabe (2001) consider a model with lower bound but assume perfect foresight. In their model the lower bound may be reached in $t=0$, but is never binding again some time onwards in the future. As is shown below, the equilibrium of a stochastic economy differs considerably from such a perfect foresight solution, because shocks may always drive the economy back into a situation with zero nominal interest rates.

\subsubsection{How much non-linearity?}

Instead of the fully nonlinear model, we study linear approximations to firms' and households' first order conditions, i.e., equations (2) and (3), respectively, and a quadratic approximation to the objective function, i.e., equation (1). This means that the only nonlinearity that we take account of is the one imposed by the zero lower bound (4). ${ }^{10}$

\footnotetext{
${ }^{10}$ Technically, this approach is equivalent to linearizing the first order conditions of the nonlinear maximization problem around the first best steady state except for the non-negativity constraint for nominal interest rates that is kept in its original nonlinear form.
} 
Clearly, this modelling approach has advantages and disadvantages. One disadvantage is that for the empirically relevant shock support and the estimated value of the discount factor the linearizations (2) and (3) may perform poorly at the lower bound. Yet, this depends on the degree of nonlinearity present in the economy, an issue about which relatively little is empirically known.

A paramount advantage of our approach is that one can economize in the dimension of the state space. A fully nonlinear setup would require an additional state to keep track over time of the higher-order effects of price dispersion, as shown by Schmitt-Grohé and Uribe (2003). Computational costs would become prohibitive with such an additional state. ${ }^{11}$ A further advantage of focusing solely on the nonlinearities induced by the lower bound is that one does not have to parameterize higher order terms when calibrating the model. This seem important, given the lack of empirical evidence on this matter.

Finally, the simpler setup implies that our results remain more easily comparable to the standard linear-quadratic analysis without lower bound that appears in the literature, as the only difference consists of imposing equation (4).

\section{Solving the Model}

This section shows how we solve the model under discretion. The solution strategy for the case with policy commitment is illustrated in Adam and Billi (2004).

We restrict attention to stationary Markov perfect equilibria in which the policy functions depend on the current predetermined states $u_{t}$ and $g_{t}$ only. ${ }^{12} \mathrm{~A}$ Markov perfect equilibrium consists of policy functions $y\left(u_{t}, g_{t}\right), \pi\left(u_{t}, g_{t}\right)$, and

\footnotetext{
${ }^{11}$ With policy commitment the model has four state variables already, i.e., the two exogenous shocks and the lagged values of the Lagrange multipliers for constraints (2) and (3), see Adam and Billi (2004) for details.

${ }^{12}$ When considering a model with lagged inflation in the Phillips curve, as in section 8 , policy functions also depend on lagged inflation rates.
} 
$i\left(u_{t}, g_{t}\right)$ that solve problem (1)-(8) when the expectations in equations (2) and (3) are given by

$$
\begin{aligned}
& E_{t} \pi_{t+1}=\int \pi\left(\rho_{u} u_{t}+\varepsilon_{u, t+1}, \rho_{g} g_{t}+\varepsilon_{g, t+1}\right) f\left(\varepsilon_{u, t+1}, \varepsilon_{g, t+1}\right) \mathrm{d}\left(\varepsilon_{u, t+1}, \varepsilon_{g, t+1}\right) \\
& E_{t} y_{t+1}=\int y\left(\rho_{u} u_{t}+\varepsilon_{u, t+1}, \rho_{g} g_{t}+\varepsilon_{g, t+1}\right) f\left(\varepsilon_{u, t+1}, \varepsilon_{g, t+1}\right) \mathrm{d}\left(\varepsilon_{u, t+1}, \varepsilon_{g, t+1}\right)
\end{aligned}
$$

where $f(\cdot, \cdot)$ is the probability density function of the innovations $\left(\varepsilon_{u}, \varepsilon_{g}\right)$.

Equations (10) and (11) show that the solution to problem (1)-(8) enters the constraints (2) and (3). Solving for the equilibrium thus requires finding a fixed-point in the space of policy functions.

We numerically solve for the fixed-point as follows. We guess initial policy functions, then compute the associated expectations in equations (10) and (11). For given expectations, problem (1)-(8) is a simple static one-period maximization problem, where the first order conditions can be used to determine updated policy functions. We iterate in this manner until convergence. The numerical procedure is described in detail in appendix A.1.

\section{Calibration to U.S. Economy}

We calibrate the model to the U.S. economy employing the parameterization of Adam and Billi (2004), which is based in turn on the results of Rotemberg and Woodford (1998) and our estimates of the U.S. shock processes for the period 1983:1-2002:4. The parameter values are summarized in table 1 and serve as the baseline calibration of the model. The implied steady state real interest rate for this parameterization is $3.5 \%$ annually.

[Table 1 about here]

Throughout the paper variables are expressed in terms of percentage point deviations from deterministic steady state values. Interest rates and inflation 
rates are expressed in annualized percentage deviations, while the real rate shock and the mark-up shock are stated in quarterly percentages.

\section{The Welfare Losses from Discretionary Policy}

Using the baseline calibration from the previous section, table 2 reports the welfare losses implied by discretionary policy. ${ }^{13}$ The table reports losses both for a model with bound and for one ignoring the lower bound. Losses are expressed in terms of their welfare equivalent permanent consumption reduction. ${ }^{14}$ As is usually the case with New Keynesian models, e.g., Galí (2003), and representative agent models more generally, e.g., Lucas (1987), the welfare losses associated with cyclical fluctuations turn out to be fairly small in absolute size. Yet, important relative differences do show up.

[Table 2 about here]

As shown in the second column of table 2, under policy commitment the consumption losses are almost independent of whether or not the zero lower bound is taken into account by the model. We find this to be a fairly robust outcome. The situation differs notably under discretionary policy, where the consumption losses relative to the case with commitment increase by about $65 \%$ once the zero lower bound is accounted for. This clarifies that one significantly understates the true welfare losses associated with discretionary monetary policy if ignoring the existence of a lower bound on nominal interest rates.

Depending on the precise model parameterization, the understatement of the consumption losses may turn out to be even larger. This is illustrated in figure 1 , which reports the increase in the consumption losses associated with taking

\footnotetext{
${ }^{13}$ The table reports unconditional welfare losses, obtained by averaging the discounted losses across 1000 simulations each 1000 periods long.

${ }^{14}$ Consumption equivalents are obtained via an appropriate transformation of the losses from objective (1), see appendix A.2.
} 
into account the zero lower bound under discretionary policy, as a function of the steady state real interest rate. ${ }^{15}$ It shows that already for steady state real interest rates slightly below the baseline value of $3.5 \%$, the true consumption loss generated by discretionary policy may be as much as 300\% higher than suggested instead by a model ignoring the zero lower bound.

[Figure 1 about here]

The dependence of the size of the consumption losses on the steady state real interest rate, displayed in figure 1 , suggests that the lower bound inflicts sizable welfare losses under discretionary policy whenever the natural real interest rate is low, i.e., for low values of the real rate shock $g_{t}$. The next sections investigate this issue in greater detail.

\section{Perfect Foresight}

To gain intuition for the numerical findings reported above, this section assumes perfect foresight and analytically determines the Markov perfect equilibrium associated with discretionary monetary policy. Analysis of the stochastic case is deferred to the next section.

For simplicity, we abstract from time variations in the mark-up shock $u_{t}$ and focus on variations of the real rate shock $g_{t}$ only. ${ }^{16}$ To characterize the discretionary equilibrium define for the real rate shock a critical value

$$
g^{c}=-\sigma r^{*}
$$

\footnotetext{
${ }^{15}$ The steady state real interest rate is varied by changing the discount factor $\beta$. Instead, all other parameters take on their baseline values from table 1 . For a steady state real interest rate below $3.29 \%$ our algorithm for computing the optimal discretionary policy fails to converge.

${ }^{16}$ For the baseline calibration of table 1, our numerical simulations show that mark-up shocks do not drive the higher welfare losses associated with taking proper account of the lower bound.
} 
and partition the real line into a number of non-intersecting intervals

$$
\begin{aligned}
& I^{0}=\left[g^{c},+\infty\right) \\
& I^{j}=\left[g^{c} /\left(\rho_{g}\right)^{j}, g^{c} /\left(\rho_{g}\right)^{j-1}\right) \quad \text { for } j=1,2,3 \ldots
\end{aligned}
$$

Under perfect foresight these intervals have the convenient property that if $g_{t} \in$ $I^{j}$ then $g_{t+1} \in I^{j-1}$ for all $j>0$. The interval $I^{0}$ is an absorbing interval that is reached in finite time for any initial value $g_{0}$.

In appendix A.3 the following result is shown:

Proposition 1 Suppose $\varepsilon_{u, t}=\varepsilon_{g, t}=0$ and $u_{0}=0$. There exists a Markov perfect equilibrium with perfect foresight such that

$$
i=\left\{\begin{array}{cc}
\frac{1}{\sigma} g & \text { for } g \geq g^{c} \\
-r^{*} & \text { for } g<g^{c}
\end{array}\right.
$$

and in which output and inflation are continuous functions of $g$. For $g \in I^{0}$ output and inflation are equal to zero. For $g \in I^{j}(j>0)$ output and inflation are negative and linearly increasing in $g$ at a rate that increases with $j$.

Figure 2 displays the equilibrium for the case with lower bound (solid line) and without lower bound (dashed line with circles), when using the U.S. baseline calibration of table $1 .^{17}$ When ignoring the lower bound real rate shocks do not generate any policy trade-off. The policymaker replicates variations in the natural real rate by adjusting nominal interest rates appropriately.

[Figure 2 about here]

Instead, with lower bound it remains optimal to mimic this policy as long as the lower bound is not reached, but to set nominal interest rates to zero once the natural real rate drops below the critical value $g^{c}$. Yet, when this happens output falls short of potential and inflation becomes negative. This occurs

\footnotetext{
${ }^{17}$ For this calibration $g^{c} \approx-5.47$.
} 
because of the lower bound real interest rates are higher than their efficient level.

Figure 2 also shows that, as stated in proposition 1, the effects of a marginal reduction of $g$ on output and inflation are increasing as the real rate becomes more negative. More negative values of $g$ imply the lower bound is reached also in the future. This induces expectations of negative output and inflation, which reinforce the downward pressure on current output and inflation associated with too high real interest rates, see equations (2) and (3).

This finding can explain the dependence of the welfare loss on the steady state real interest rate, illustrated earlier in figure 1. A lower steady state real interest rate $r^{*}$ leads to an increase in the critical value $g^{c}$, see equation (12), and causes output losses and negative inflation rates over a wider range of real rate shocks. None of these losses show up in a model that ignores the existence of the zero lower bound.

\section{Stochastic Equilibrium}

This section presents the stochastic Markov perfect equilibrium with lower bound corresponding to the baseline parameterization in table 1 . In particular, we find that the presence of shocks leads to significant differences from the case with perfect foresight considered in the previous section.

\subsection{Impact on Average Values}

We first discuss the effect of the zero lower bound on average output and inflation under discretionary policy. Since the lower bound causes the model to be nonlinear, the average values of endogenous variables will generally differ from their steady state values due to a breakdown of certainty equivalence.

[Figure 3 about here] 
The perfect foresight solution presented earlier in section 6 suggests that both average output and inflation should fall short of their steady state value of zero. Figure 3 depicts the average values of output and inflation under discretionary policy at different levels of the steady state real interest rate. ${ }^{18}$ As suggested by the perfect foresight solution, there is more deflation on average as the steady state real interest rate falls. Surprisingly, however, average output is above potential, unlike suggested by figure 2 for the case with perfect foresight.

The origin of these results is clarified in the next section, which looks at the stochastic equilibrium in greater detail.

\subsection{Equilibrium Response to Shocks}

We first discuss the response to mark-up shocks and then discuss that to real rate shocks.

We find that the zero lower bound does not represent a binding constraint in the model when dealing with mark-up shocks. The empirical variability of these shocks is simply too small for the policy constraint to matter. Figure 4 displays the equilibrium response of output, inflation, and nominal interest rates to mark-up shocks. ${ }^{19}$ The solid line corresponds to the optimal responses if the bound is considered, while the dashed line refers to the case where the lower bound is ignored. The figure shows that the optimal reaction to mark-up shocks is virtually unaffected by the presence of the zero lower bound. Moreover, interest rates remain well above their lower bound, even for very negative values of the mark-up shock.

[Figure 4 about here]

\footnotetext{
${ }^{18}$ The steady state interest rate is varied by changing the discount factor $\beta$. All other parameters take on their baseline values from table 1 .

${ }^{19}$ The figure depicts responses over a range of \pm 3 unconditional standard deviations of the mark-up shock; with the value of the real rate shock set equal to zero.
} 
The situation differs notably when considering real-rate shocks. Figure 5 depicts the equilibrium response of output, inflation, and nominal rates to a real rate shock. ${ }^{20}$ The solid line corresponds to the stochastic case while the dashed line corresponds to the case with perfect foresight, considered in section 6. The figure reveals a number of interesting features.

[Figure 5 about here]

First, while large negative values of the real rate shock result in negative output gaps and deflation, these effects are much more pronounced in the stochastic case. Compared to the case with perfect foresight, both the maximum output losses and deflation approximately triple.

Second, the zero lower bound is now reached much earlier than under perfect foresight, since interest rates are lowered more aggressively in response to negative real rate shocks. For our baseline calibration the presence of the lower bound might require setting nominal interest rates up to 75 basis points lower than under perfect foresight.

Third, figure 5 reveals that the output gap becomes slightly positive and inflation slightly negative well before the zero lower bound is reached. Thus real rate shocks generate a policy trade off even at times where nominal interest rates are still positive.

All these features emerge because in a fully stochastic setup shocks may drive the economy from a situation with positive nominal interest rates into one where the lower bound is reached. Since output and inflation become negative once at zero nominal rates, the possibility of reaching the lower bound in the future causes agents to reduce their expectations of future output and inflation

\footnotetext{
${ }^{20}$ The figure displays the responses up to a -3 unconditional standard deviation value of the real rate shock; assuming mark-up shocks to be at zero.
} 
well before interest rates are at the lower bound. ${ }^{21}$ The reduction in expected output and inflation is isomorphic to a negative mark-up shock and a negative real rate shock in equations (2) and (3), respectively. To both these shocks the policymaker responds by lowering nominal interest rates. This explains the more aggressive reduction of interest rates in the lower panel of figure 5 .

Negative mark-up shocks, however, generate a policy trade-off and policy responds to them by letting output rise and inflation fall, see figure 4 . The downward bias in expectations, therefore, also explains the output boom that can be observed in the 'run-up' to zero nominal rates in figure 5 , i.e., before $g_{t}$ enters the binding area. This output boom compensates for the output losses occurring for more negative shock values and explains why in the stochastic case there is virtually no distortion of the average output level, see figure 3.

Finally, the downward bias of expected future values of output and inflation, due to the presence of shocks, generates downward pressure for corresponding actual values. This in turn justifies even lower expectations. This complementarity between expectations and outcomes explains the large differences in magnitudes implied by the perfect foresight equilibrium and the stochastic equilibrium.

\subsection{Comparison to the case with commitment}

This section briefly summarizes results derived in Adam and Billi (2004), and explains why under commitment taking into account the existence of the zero lower bound does not generate large welfare consequences.

[Figure 6 about here]

Figure 6 displays the average values of output and inflation as a function of the steady state real interest rate. Unlike in the case with discretion, average

\footnotetext{
${ }^{21}$ Technically, since the policy functions of output and inflation depicted in figure 2 are concave, Jensen's inequality implies a downward bias once we allow for uncertainty about the future value of the natural real rate.
} 
inflation does not fall as the level of the real interest rate is lower. For very low levels of the real interest rate the average inflation rate even becomes slightly positive. This suggests that under commitment output and inflation fall much less in response to a negative real rate shock.

[Figure 7 about here]

This point is illustrated in figure 7 which depicts the equilibrium response of output and inflation to a negative real rate shock. The solid line shows the responses under commitment, while the dashed line corresponds to the case with discretion. The difference in the responses of output and inflation is sizable. It emerges because under commitment the policymaker can engage in (credible) promises about the conduct of monetary policy in the future. In particular, once the lower bound is reached, the policymaker promises to allow for some inflation in the future. This raises expectations of future inflation, which reduces real interest rates and helps stabilizing current inflation and output. Since the inflation promises fail to be time-consistent, they are unavailable to a discretionary policymaker.

\section{Sensitivity Analysis}

In this section we report the results of robustness exercises regarding the model specification and parameterization.

\subsection{Hybrid Phillips Curve}

In the benchmark model considered thus far inflation is assumed to be purely forward-looking. Yet, a number of econometric studies suggest that inflation is partly determined by lagged inflation rates, e.g., Galí and Gertler (1999).

This section studies the implications of allowing inflation to depend on lagged inflation rates. In particular, we replace the forward-looking Phillips curve (2) 
by its 'hybrid' version

$$
\pi_{t}=\frac{1}{1+\beta \gamma}\left[\beta E_{t} \pi_{t+1}+\gamma \pi_{t-1}+\kappa y_{t}+u_{t}\right]
$$

where $\gamma \geq 0$ is an 'indexation parameter' that indicates the degree to which firms automatically adjust their prices to lagged inflation rates when they do not fully reoptimize prices, see Woodford (2003). Correspondingly, we also replace the objective function (1) by

$$
-E_{0} \sum_{i=0}^{\infty} \beta^{i}\left(\left(\pi_{t+i}-\gamma \pi_{t+i-1}\right)^{2}+\lambda y_{t+i}^{2}\right)
$$

which Woodford (2003) shows to be a second order approximation to the household's utility function when the Phillips curve is given by equation (14).

To economize on the number of the state variables we abstract from mark-up shocks in the model, i.e., we set $u_{t} \equiv 0$ in equation (14). ${ }^{22}$ This simplification implies welfare losses emerge only if the lower bound is taken into account, independently of the degree of indexation. ${ }^{23}$ For $\gamma=0$ the policy problem reduces to the simpler case considered in the previous sections, except for the fact that we now abstract from mark-up shocks. For $\gamma>0$ inflation is partly determined by lagged inflation, which becomes an endogenous state variable of the system. Solving the policy problem is then more involved, since the discretionary maximization problem fails to be static.

We consider stationary Markov-perfect equilibria where output, inflation, and nominal interest rates depend on the exogenous shocks $(u, g)$ and also on the lagged inflation rate $\pi_{-1}$. The current policymaker behaves as a Stackelberg leader and rationally anticipates how future equilibrium values respond to current inflation outcomes. Constraint (8) thus has to be replaced by

$$
\left\{y\left(s_{t+i}\right), \pi\left(s_{t+i}\right), i\left(s_{t+i}\right)\right\} \text { given for } i \geq 1 \text {, where } s_{t+i}=\left(u_{t+i}, g_{t+i}, \pi_{t+i-1}\right)
$$

\footnotetext{
${ }^{22} \mathrm{An}$ additional state variable would raise the dimension of the state space of the model to five in the case with commitment. Computational costs would thus be prohibitive.

${ }^{23}$ When ignoring the lower bound, the optimal policy response to real rate shocks is timeconsistent. Discretionary monetary policy then does not generate welfare losses.
} 
Appendix A.4 illustrates the numerical algorithm we employ to solve the model under discretion, based on a value function representation of the policy problem. It can be seen as a generalization to a nonlinear setup of the technique described in Söderlind (1999). Instead, the solution strategy for solving the policy problem under commitment is described in Billi (2004).

[Figure 8 about here]

Figure 8 depicts the steady state consumption losses from discretionary policy associated with various degrees of indexation $\gamma \cdot{ }^{24}$ The consumption losses are expressed in terms of the percentage increase relative to the loss without indexation $(\gamma=0)$. As shown, the consumption losses are strongly increasing in the degree of indexation, e.g., with $\gamma=0.16$, the loss from discretionary policy is almost $300 \%$ higher than in the case without indexation. ${ }^{25}$

[Figure 9 about here]

Moreover, figure 9 compares the equilibrium responses for the purely forwardlooking case (solid line) to the case where $\gamma=0.16$ (dashed line). Endogenous inflation persistence significantly increases the amount of deflation and the size of output losses associated with negative values of the real rate shock. Also, the policymaker has to ease monetary policy even more aggressively than in a purely forward-looking specification. This is in line with findings by Coenen et al. (2004) and Wolman (2005) who report that interest rate rules that stabilize the inflation rate lead to significant real distortions whenever price or wage setting frictions impart inertia to the inflation rate.

Overall, this suggests that endogenous inflation persistence considerably reinforces the results obtained for the purely forward-looking model: by ignoring the zero lower bound one understates the value of monetary commitment.

\footnotetext{
${ }^{24}$ The figure uses the baseline values from table 1 for the remaining parameters.

${ }^{25}$ For values of $\gamma$ larger than 0.16 our numerical algorithm for computing the optimal discretionary policy then fails to converge.
} 


\subsection{Lower Interest Rate Elasticity of Output}

Our benchmark calibration of table 1 assumes an interest rate elasticity of output of $\sigma=6.25$, which seems to lie on the high side for plausible estimates of the intertemporal elasticity of substitution. ${ }^{26}$ Therefore, we also consider a calibration with $\sigma=1$, that corresponds to log utility in consumption, and constitutes the usual benchmark parameterization in the real business cycle literature. This calibration is taken from our companion paper, see Adam and Billi (2004), and is summarized in table 3 .

[Tables 3 and 4 about here]

Table 4 reports the consumption equivalent welfare losses associated with discretionary monetary policy. As for the benchmark calibration, losses remain almost unchanged when taking into account the zero lower bound under commitment. The losses under discretion, however, increase markedly. The increase is much stronger than for the benchmark calibration because for $\sigma=1$ the data imply a slightly more variable natural real rate process. This causes the lower bound to be reached more often.

\section{Conclusions and Outlook}

We show that taking explicitly into account the existence of the zero lower bound on nominal interest rates considerably increases the welfare costs associated with discretionary monetary policy. In particular, low values of the natural real rate of interest cause larger much output losses and stronger deflation than in the case with policy commitment. Importantly, none of these feature is appropriately accounted for by models that ignore the lower bound.

In the benchmark New Keynesian model that we employ, once the lower bound is reached the inability to commit to future policy actions deprives discretionary monetary policymakers of their policy instruments. However, in practice

\footnotetext{
${ }^{26}$ As argued by Woodford (2003), a high elasticity value may capture non-modeled interest-
} rate-sensitive investment demand. 
there are several alternative policy instruments that might still be available in a situation of zero nominal interest rates, most notably fiscal policy and exchange rate policy. We plan to investigate the relevance of these other policy instruments by including them into our analysis in future work.

\section{A Appendix}

\section{A.1 Numerical algorithm (forward-looking Phillips curve)}

To solve problem (1)-(8), we define a grid of $N$ interpolation nodes over the state space $(u, g) \subset R^{2}$ and evaluate policy functions $y(u, g), \pi(u, g)$, and $i(u, g)$ at intermediate values resorting to linear interpolation. The expectations defined by equations (10) and (11) are evaluated at each interpolation node using an $M$ node Gaussian-Hermite quadrature scheme. ${ }^{27}$ Our numerical algorithm consists of the following steps:

Step 1: Choose the degree of approximation $N$ and $M$ and assign the interpolation and quadrature nodes. Guess initial values for the policy functions $y^{0}, \pi^{0}$, and $i^{0}$ at the interpolation nodes.

Step 2: At each interpolation node compute the expectations (10) and (11) implied by the current guess $y^{k}, \pi^{k}$, and $i^{k}$. Then employ the first order conditions of (1)-(8) to derive a new guess for the policy functions in the following way. At each interpolation node, first assume $i>-r^{*}$. The first order conditions then imply the well-known 'targeting rule'

$$
\pi=-\frac{\lambda}{\kappa} y
$$

This together with (2) delivers the implied values for $y$ and $\pi$. Plugging these into (3) determines the value of $i$. If $i>-r^{*}$, as initially conjectured, one has found a solution. Otherwise, set $i=-r^{*}$ and solve (2) and (3) for

\footnotetext{
${ }^{27}$ See chapter 7 in Judd (1998) for details.
} 
$y$ and $\pi$. Performing this at each node delivers a new guess $y^{k+1}, \pi^{k+1}$, and $i^{k+1}$.

Step 3: Stop if $\max \left\{\left|y^{k}-y^{k+1}\right|_{\max },\left|\pi^{k}-\pi^{k+1}\right|_{\max },\left|i^{k}-i^{k+1}\right|_{\max }\right\}<\tau$ where $|\cdot|_{\max }$ denotes the maximum absolute norm and $\tau>0$ the convergence tolerance level. Otherwise repeat step 2.

In our application we set $N=275$ and $M=9$. Relatively more nodes are placed in areas of the state space where the policy functions display kinks, i.e., at negative values of the $g$ shock where the lower bound is reached. The support of the interpolation nodes is chosen to cover \pm 4 unconditional standard deviations for each of the exogenous shocks. Our initial guess for the policies is set to the solution of the problem without zero lower bound. The tolerance level is $\tau=1.49 \cdot 10^{-8}$, i.e., the square root of machine precision.

\section{A.2 Computing welfare equivalent consumption losses}

The results in chapter 6 of Woodford (2003) show that a second order approximation of the representative agent's discounted utility is given by

$$
U=-\bar{Y} U_{c} L
$$

where $\bar{Y}$ denotes steady state output, $U_{c}>0$ steady state marginal utility of consumption, and

$$
L=\frac{1}{2} \frac{\alpha \theta(1+\omega \theta)}{(1-\alpha)(1-\alpha \beta)} \sum_{i=0}^{\infty} \beta^{i}\left(\pi_{t+i}^{2}+\lambda y_{t+i}^{2}\right)
$$

Note that, up to a change in sign, the infinite sum appearing in the previous expression corresponds to the discounted loss (1).

Assuming a permanent reduction in consumption by $p \geq 0$ percent, a second order approximation of the utility loss generated is given by

$$
\begin{aligned}
\frac{1}{1-\beta}\left(-U_{c} \bar{Y} \frac{p}{100}+U_{c c}\left(\bar{Y} \frac{p}{100}\right)^{2}\right) & =-\frac{U_{c} \bar{Y}}{1-\beta}\left(\frac{p}{100}-\frac{U_{c c} \bar{Y}}{U_{c}}\left(\frac{p}{100}\right)^{2}\right) \\
& =-\frac{U_{c} \bar{Y}}{1-\beta}\left(\frac{p}{100}+\frac{1}{\sigma}\left(\frac{p}{100}\right)^{2}\right)
\end{aligned}
$$


where $U_{c c}<0$ is the second derivative of utility with respect to consumption evaluated at the steady state. Equating this utility loss to $U$ delivers

$$
\frac{1}{\sigma}\left(\frac{p}{100}\right)^{2}+\frac{p}{100}-(1-\beta) L=0
$$

The utility equivalent percentage loss in steady state consumption is then

$$
p=100 \cdot \sigma \frac{-1+\sqrt{1+\frac{4(1-\beta) L}{\sigma}}}{2}
$$

Since we express $y$ and $\pi$ in percentage points, we have to rescale the losses and use

$$
p=100 \cdot \sigma \frac{-1+\sqrt{1+\frac{4(1-\beta) L}{\sigma 100^{2}}}}{2}
$$

Analogous arguments apply for the model with a hybrid Phillips curve. Equation (19) then still applies, but (18) is substituted with

$$
L=\frac{1}{2} \frac{\alpha \theta(1+\omega \theta)}{(1-\alpha)(1-\alpha \beta)}\left[\sum_{i=0}^{\infty} \beta^{i}\left(\left(\pi_{t+i}-\gamma \pi_{t+i-1}\right)^{2}+\lambda y_{t+i}^{2}\right)\right]
$$

\section{A.3 Proof of proposition 1}

Suppose $g \in I^{0}$, then $g^{\prime} \in I^{0}$ where $g^{\prime}$ denotes the value of $g$ in the subsequent period. Given the interest rate policy (13), equations (2) and (3) imply that $\pi=y=0$ constitutes a perfect foresight equilibrium for all $g \in I^{0}$. Clearly, the interest rate policy (13) is optimal for all $g \in I^{0}$.

Now suppose $g \in I^{1}$. Since this implies $g^{\prime} \in I^{0}$, we can solve the problem by backward induction: $g^{\prime} \in I^{0}$ implies private sector's expectations are given by $E \pi^{\prime}=E y^{\prime}=0$. It then follows from equations (2), (3), and (13) that

$$
\begin{aligned}
& y=-g^{c}+g \\
& \pi=-\kappa g^{c}+\kappa g
\end{aligned}
$$

Note that output and inflation are continuous in the transition from $I^{1}$ to $I^{0}$, and linear in $g$ for $g \in I^{1}$. One can iterate in this manner to obtain output and 
inflation for $I^{2}, I^{3}, \ldots$ Continuity and linearity of all equations involved thereby implies that output and inflation are continuous functions of $g$. Moreover, for the stated interest rate policy, in each interval $I^{j}$ output and inflation are linear in $g$ and can be represented as

$$
\begin{aligned}
& y=c_{y}^{j}+s_{y}^{j} g \\
& \pi=c_{\pi}^{j}+s_{\pi}^{j} g
\end{aligned}
$$

Equations (20) and (21) imply

$$
\left(\begin{array}{l}
s_{y}^{1} \\
s_{\pi}^{1}
\end{array}\right)=\left(\begin{array}{c}
1 \\
\kappa
\end{array}\right)
$$

Using equations (22) and (23) and the law of motion of $g$ to construct expectations in the interval $I^{j+1}$, equations (2) and (3) and the interest rate policy gives

$$
\begin{aligned}
\left(\begin{array}{c}
s_{y}^{j+1} \\
s_{\pi}^{j+1}
\end{array}\right) & =\left(\begin{array}{l}
s_{y}^{1} \\
s_{\pi}^{1}
\end{array}\right)+A\left(\begin{array}{l}
s_{y}^{j} \\
s_{\pi}^{j}
\end{array}\right) \text { where } \\
A & =\left(\begin{array}{cc}
\rho_{g} & \sigma \rho_{g} \\
\rho_{g} \kappa & \rho_{g}(\kappa \sigma+\beta)
\end{array}\right)
\end{aligned}
$$

Iterating on this equation implies that

$$
\begin{aligned}
& s^{2}=s^{1}+A s^{1} \\
& s^{3}=s^{2}+A^{2} s^{1} \\
& s^{4}=s^{3}+A^{3} s^{1}
\end{aligned}
$$

where

$$
s^{j} \equiv\left(\begin{array}{c}
s_{y}^{j} \\
s_{\pi}^{j}
\end{array}\right)
$$

Given that $s^{1}>0$ and all entries in $A$ are positive, the slopes $s^{j}$ are increasing in $j$. Since output and inflation are negative for $g \in I^{1}$, from continuity it follows that they are negative for all $g \in I^{j}$ with $j>1$. Therefore, zero nominal interest rates are optimal for $g \in I^{j}$ with $j>1$, since positive nominal interest rates would generate even lower output levels and inflation rates. 


\section{A.4 Numerical algorithm (hybrid Phillips curve)}

We define a grid of $N$ interpolation nodes over the state space $\left(u, g, \pi_{-1}\right) \subset$ $R^{3}$. Associated with the policy functions $\pi\left(u, g, \pi_{-1}\right)$ and $y\left(u, g, \pi_{-1}\right)$ are the expectation functions

$$
\begin{aligned}
& E \pi_{+1}=\int \pi\left(\rho_{u} u+\varepsilon_{u,+1}, \rho_{g} g+\varepsilon_{g,+1}, \pi\right) f\left(\varepsilon_{u,+1}, \varepsilon_{g,+1}\right) \mathrm{d}\left(\varepsilon_{u,+1}, \varepsilon_{g,+1}\right) \\
& E y_{+1}=\int y\left(\rho_{u} u+\varepsilon_{u,+1}, \rho_{g} g+\varepsilon_{g,+1}, \pi\right) f\left(\varepsilon_{u,+1}, \varepsilon_{g,+1}\right) \mathrm{d}\left(\varepsilon_{u,+1}, \varepsilon_{g,+1}\right)
\end{aligned}
$$

where $f(\cdot, \cdot)$ is the probability density function of the stochastic shock innovations $\left(\varepsilon_{u}, \varepsilon_{g}\right)$. The expectations (24) and (25) are evaluated at each interpolation node using an $M$ node Gaussian-Hermite quadrature scheme. ${ }^{28}$ Our numerical algorithm then performs the following steps:

Step 1: Choose the degree of approximation $N$ and $M$ and assign the interpolation and quadrature nodes. Guess initial values for the policy functions $y^{0}, \pi^{0}$, and $i^{0}$ at the interpolation nodes.

Step 2: At each interpolation node compute the expectations (24) and (25) implied by the current guess $y^{k}, \pi^{k}$, and $i^{k}$. For given expectation functions, the Lagrangian for maximizing (15) subject to (3)-(7), (14) and (16) can be written as a recursive saddle point problem

$$
\begin{aligned}
V^{k}\left(u, g, \pi_{-1}\right) & =\max _{(y, \pi, i)} \min _{\left(m_{1}, m_{2}\right)} h^{k}\left(u, g, \pi_{-1}, y, \pi, i, m_{1}, m_{2}, E^{k} \pi_{+1}, E^{k} y_{+1}\right) \\
& +\beta E V^{k}\left(u_{+1}, g_{+1}, \pi\right) \\
\text { s.t. } & \\
i & \geq-r^{*} \\
u_{+1} & =\rho_{u} u+\varepsilon_{u,+1} \\
g_{+1} & =\rho_{g} g+\varepsilon_{g,+1}
\end{aligned}
$$

\footnotetext{
${ }^{28}$ See chapter 7 in Judd (1998) for details.
} 
where

$$
\begin{aligned}
h^{k}(\cdot) & =-\pi^{2}-\lambda y^{2}+m_{1}\left[\pi-\frac{1}{1+\beta \gamma}\left(\beta E^{k} \pi_{+1}+\gamma \pi_{-1}+\kappa y+u\right)\right] \\
& +m_{2}\left[y-E^{k} y_{+1}+\sigma\left(i-E^{k} \pi\right)-g\right]
\end{aligned}
$$

and $m_{1}$ and $m_{2}$ are the Lagrange multipliers. Using the collocation method one can numerically solve for the fixed-point of (26) and the associated optimal policy functions $y^{k+1}, \pi^{k+1}, i^{k+1}, m_{1}^{k+1}, m_{2}^{k+1}$. Details of this procedure are described, e.g., in appendix A.2 in our companion paper, see Adam and Billi (2004).

Step 3: Stop if the maximum of $\left|y^{k}-y^{k+1}\right|_{\max },\left|\pi^{k}-\pi^{k+1}\right|_{\max },\left|i^{k}-i^{k+1}\right|_{\max }$, $\left|m_{1}^{k}-m_{1}^{k+1}\right|_{\max }$ and $\left|m_{2}^{k}-m_{2}^{k+1}\right|_{\max }$ is smaller than $\tau$, where $|\cdot|_{\max }$ denotes the maximum absolute norm evaluated at the interpolation nodes and $\tau>0$ the convergence tolerance level. Otherwise repeat step 2 .

In our application we set $N=1375$ and $M=9$. Relatively more nodes are placed in areas of the state space where the value and policy functions display a higher degree of curvature and kinks, respectively. The support of the interpolation nodes is chosen to cover \pm 4 unconditional standard deviations for each of the exogenous shocks, and to insure that all values of $\pi_{-1}$ lie inside the state space when using the solution to perform stochastic simulations. Since this can only be verified after the solution is achieved some experimentation is necessary. Our initial guess for the polices is set to the solution of the model without zero lower bound. The tolerance level is $\tau=1.49 \cdot 10^{-8}$, i.e., the square root of machine precision.

\section{References}

Adam, Klaus and Roberto M. Billi, "Optimal Monetary Policy under Commitment with a Zero Bound on Nominal Interest Rates," Center for Financial Studies, Frankfurt, Germany, Working Paper 13/2004, 2004. 
Albanesi, Stefania, V. V. Chari, and Larry Christiano, "Expectation Traps and Monetary Policy," Review of Economic Studies, 2003, 70, 715742 .

Auerbach, Alan J. and Marurice Obstfeld, "The Case for Open-Market Purchases in a Liquidity Trap," NBER Working Paper No. 9814, 2003.

Barro, Robert and David B. Gordon, "A Positive Theory of Monetary Policy in a Natural Rate Model," Journal of Political Economy, 1983, 91, 589-610.

Billi, Roberto M., "The Optimal Inflation Buffer with a Zero Bound on Nominal Interest Rates," University of Frankfurt mimeo, 2004.

Calvo, Guillermo A., "Staggered Contracts in a Utility-Maximizing Framework," Journal of Monetary Economics, 1983, 12, 383-398.

Clarida, Richard, Jordi Galí, and Mark Gertler, "The Science of Monetary Policy: Evidence and Some Theory," Journal of Economic Literature, 1999, 37, 1661-1707.

Coenen, Günter and Volker Wieland, "The Zero-Interest-Rate Bound and the Role of the Exchange Rate for Monetary Policy in Japan," Journal of Monetary Economics, 2003, 50, 1071-1101.

_ , Athanasios Orphanides, and Volker Wieland, "Price Stability and Monetary Policy Effectiveness When Nominal Interest Rates are Bounded at Zero," Advances in Macroeconomics, 2004, 4(1) article 1.

Eggertsson, Gauti, "The Deflation Bias and Committing to Being Irresponsible," Journal of Money, Credit, and Banking (forthcoming), 2005. and Michael Woodford, "Optimal Monetary Policy in a Liquidity Trap," NBER Working Paper No. 9968, 2003.

Galí, Jordi, "New Perspectives on Monetary Policy, Inflation, and the Business Cycle," in Mathias Dewatripont, Lars Peter Hansen, and Stephen 
Turnovsky, eds., Advances in Economics and Econometrics, Econometric Society Monographs, Cambridge University Press, 2003, pp. 151-197.

— and Mark Gertler, "Inflation Dynamics: A Structural Econometric Analysis," Journal of Monetary Economics, 1999, 44, 195-222.

Giannoni, Marc and Michael Woodford, "Optimal Interest Rate Rules: I. General Theory," NBER Working paper No. 9419, 2003.

Jeanne, Olivier and Lars E.O. Svensson, "Credible Commitment to Optimal Escape from a Liquidity Trap: The Role of the Balance Sheet of an Independent Central Bank," Princeton University mimeo, 2004.

Judd, Kenneth L., Numerical Methods in Economics, Cambridge: MIT Press, 1998.

Jung, Taehun, Yuki Teranishi, and Tsutomu Watanabe, "Zero Bound on Nominal Interest Rates and Optimal Monetary Policy," 2001. Kyoto Institute of Economic Research Working Paper No. 525.

King, Robert G. and Alexander L. Wolman, "Monetary Discretion, Pricing Complementarity and Dynamic Multiple Equilibria," NBER Working Paper No. 9929, 2003.

Krugman, Paul R., "It's Baaack: Japan's Slump and the Return of the Liquidity Trap," Brookings Papers on Economic Activity, 1998, 49(2), 137205.

Kydland, Finn E. and Edward C. Prescott, "Rules Rather Than Discretion: The Inconsistency of Optimal Plans," Journal of Political Economy, 1977, 85, 473-492.

Lucas, Robert E., Models of Business Cycles, Oxford: Basil Blackwell, 1987.

Rotemberg, Julio J., "The New Keynesian Microfoundations," NBER Macroeconomics Annual, 1987, 2, 69-104. 
_ and Michael Woodford, "An Optimization-Based Econometric Model for the Evaluation of Monetary Policy," NBER Macroeconomics Annual, 1998, 12, 297-346.

Schmitt-Grohé, Stephanie and Martín Uribe, "Optimal Simple and Implementable Monetary and Fiscal Rules," Duke University Mimeo, 2003.

Söderlind, Paul, "Solution and Estimation of RE Macromodels with Optimal Policy," European Economic Review, 1999, 43, 813-823.

Svensson, Lars E. O., "Escaping from a Liquidity Trap and Deflation: The Foolproof Way and Others," Journal of Economic Perspectives, 2003, $17(4), 145-166$.

Wolman, Alexander L., "Real Implications of the Zero Bound on Nominal Interest Rates," forthcoming Journal of Money Credit and Banking, 2005.

Woodford, Michael, Interest and Prices, Princeton: Princeton University Press, 2003. 


\begin{tabular}{c|l|l} 
Parameter & Economic interpretation & Assigned value \\
\hline$\beta$ & quarterly discount factor & $\left(1+\frac{3.5 \%}{4}\right)^{-1} \approx 0.9913$ \\
$\sigma$ & real rate elasticity of output & 6.25 \\
$\alpha$ & share of firms keeping prices fixed & 0.66 \\
$\theta$ & price elasticity of demand & 7.66 \\
$\omega$ & elasticity of firms' marginal costs & 0.47 \\
$\kappa$ & slope of the Phillips curve & 0.024 \\
$\lambda$ & weight on output in the loss function & $\frac{0.048}{4^{2}}=0.003$ \\
\hline$\rho_{u}$ & AR-coefficient mark-up shocks & 0 \\
$\rho_{g}$ & AR-coefficient real rate shocks & 0.8 \\
$\sigma_{u}$ & s.d. mark-up shock innovations (quarterly \%) & 0.154 \\
$\sigma_{g}$ & s.d. real rate shock innovations (quarterly \%) & 1.524
\end{tabular}

Table 1: Parameter values (baseline calibration)

\begin{tabular}{l|c|c||c|}
$\begin{array}{c}\text { Consumption equivalents } \\
\text { (in percent) }\end{array}$ & $\begin{array}{c}\text { Loss under } \\
\text { commitment }\end{array}$ & $\begin{array}{c}\text { Loss under } \\
\text { discretion }\end{array}$ & $\begin{array}{c}\text { Additional loss } \\
\text { from discretion }\end{array}$ \\
\hline Without zero bound & -0.0152 & -0.0197 & -0.0045 \\
With zero bound & -0.0153 & -0.0228 & -0.0075 \\
\hline \hline & & & \\
Increase in additional loss & & & $+65 \%$ \\
\hline
\end{tabular}

Table 2: Welfare equivalent consumption losses from discretion (baseline calibration) 


\begin{tabular}{c|l|l} 
Parameter & Economic interpretation & Assigned value \\
\hline$\beta$ & quarterly discount factor & $\left(1+\frac{3.5 \%}{4}\right)^{-1} \approx 0.9913$ \\
$\sigma$ & real rate elasticity of output & 1 \\
$\alpha$ & share of firms keeping prices fixed & 0.66 \\
$\theta$ & price elasticity of demand & 7.66 \\
$\omega$ & elasticity of firms' marginal costs & 0.47 \\
$\kappa$ & slope of the Phillips curve & 0.057 \\
$\lambda$ & weight on output in the loss function & 0.007 \\
\hline$\rho_{u}$ & AR-coefficient mark-up shocks & 0.36 \\
$\rho_{g}$ & AR-coefficient real rate shocks & 0.8 \\
$\sigma_{u}$ & s.d. mark-up shock innovations (quarterly \%) & 0.171 \\
$\sigma_{g}$ & s.d. real rate shock innovations (quarterly \%) & 0.294
\end{tabular}

Table 3: Parameter values (RBC calibration)

\begin{tabular}{l|c|c||c|}
$\begin{array}{c}\text { Consumption equivalents } \\
\text { (in percent) }\end{array}$ & $\begin{array}{c}\text { Loss under } \\
\text { commitment }\end{array}$ & $\begin{array}{c}\text { Loss under } \\
\text { discretion }\end{array}$ & $\begin{array}{c}\text { Additional loss } \\
\text { from discretion }\end{array}$ \\
\hline Without zero bound & -0.0258 & -0.0400 & -0.0142 \\
& -0.0259 & -0.0668 & -0.0408 \\
With zero bound & & & $+189 \%$ \\
\hline \hline
\end{tabular}

Table 4: Welfare equivalent consumption losses from discretion (RBC calibration) 


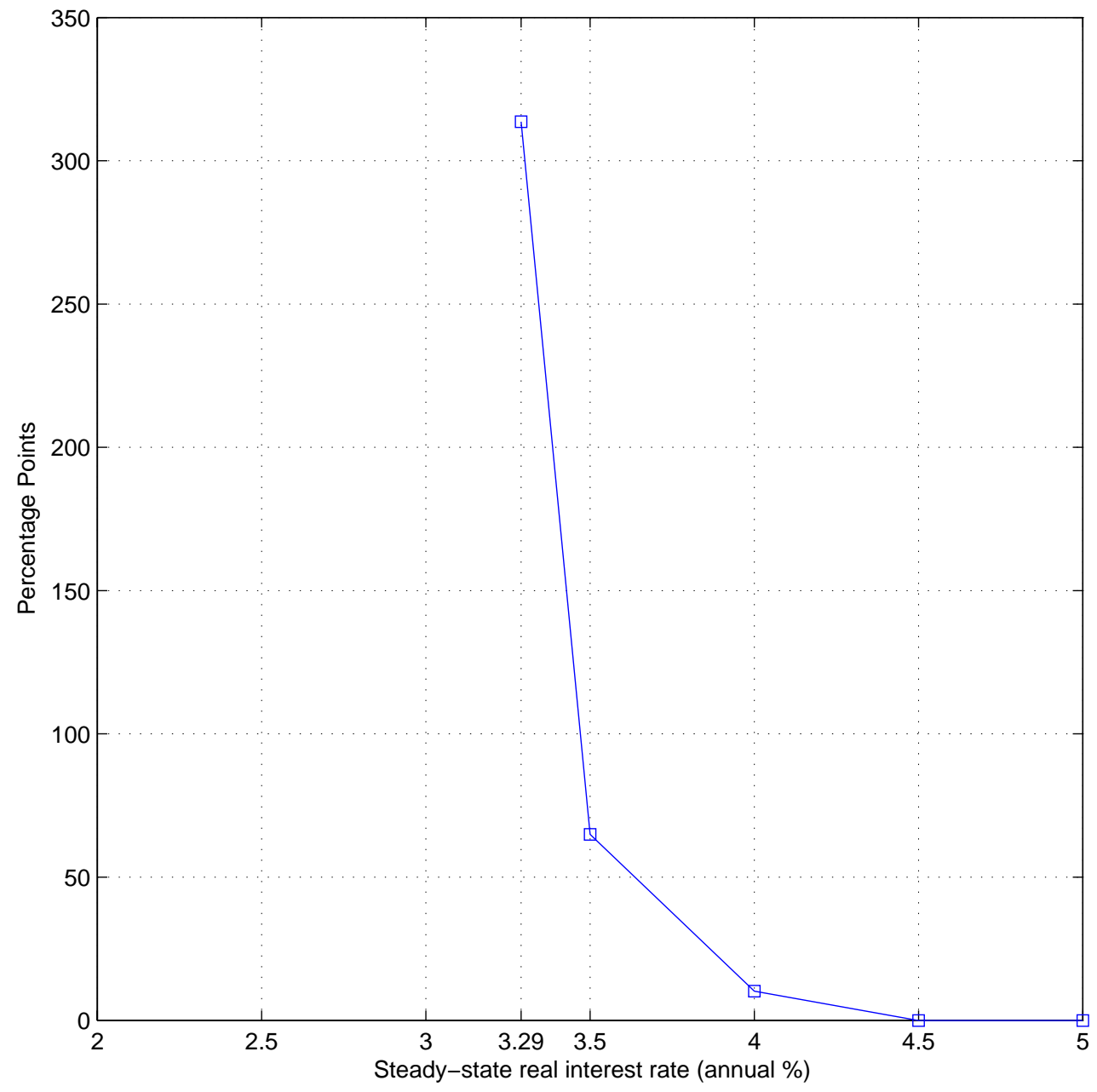

Figure 1: Increase in consumption losses taking into account the zero lower bound (discretionary policy) 

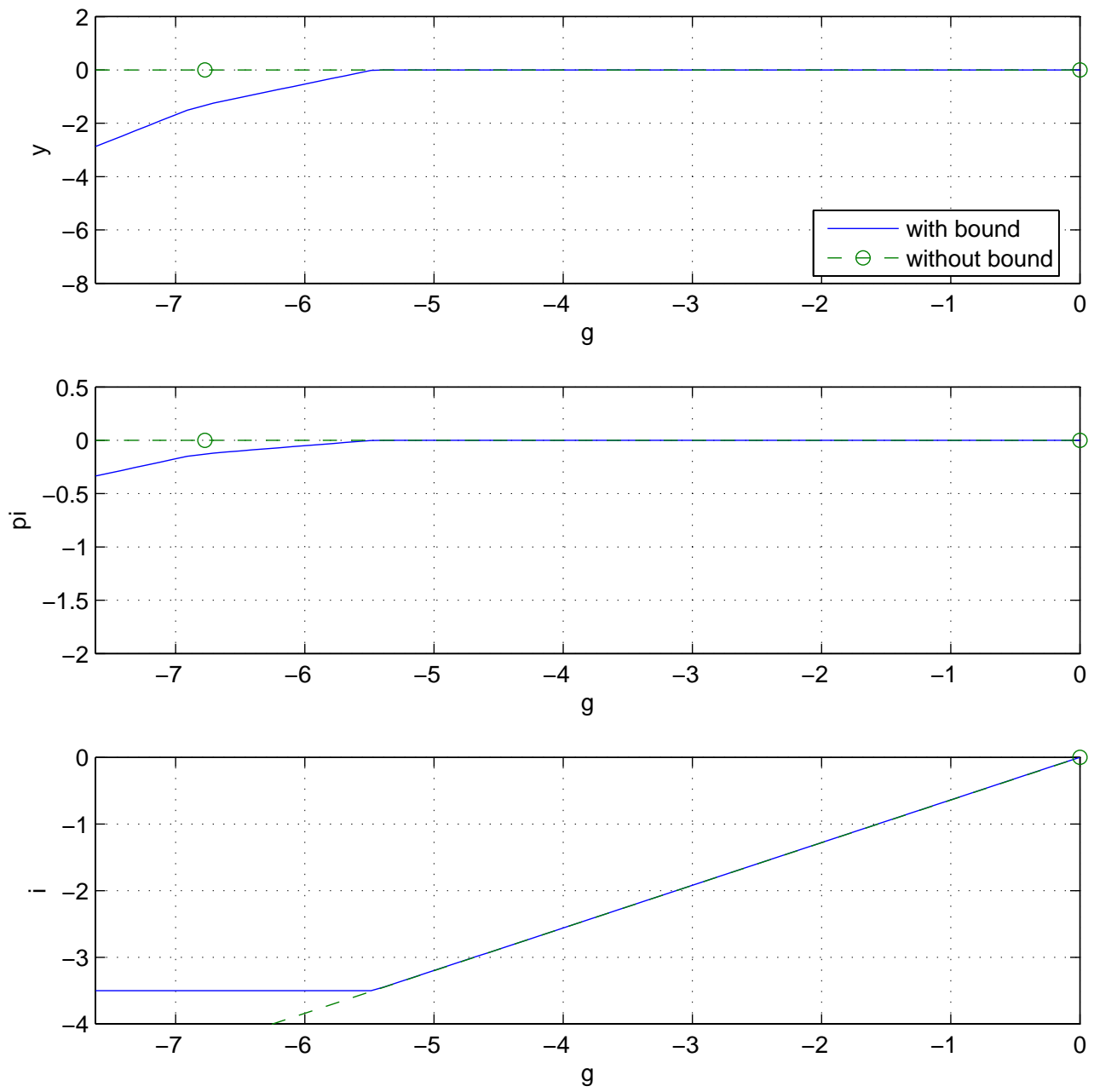

Figure 2: Perfect foresight equilibrium (discretionary policy) 

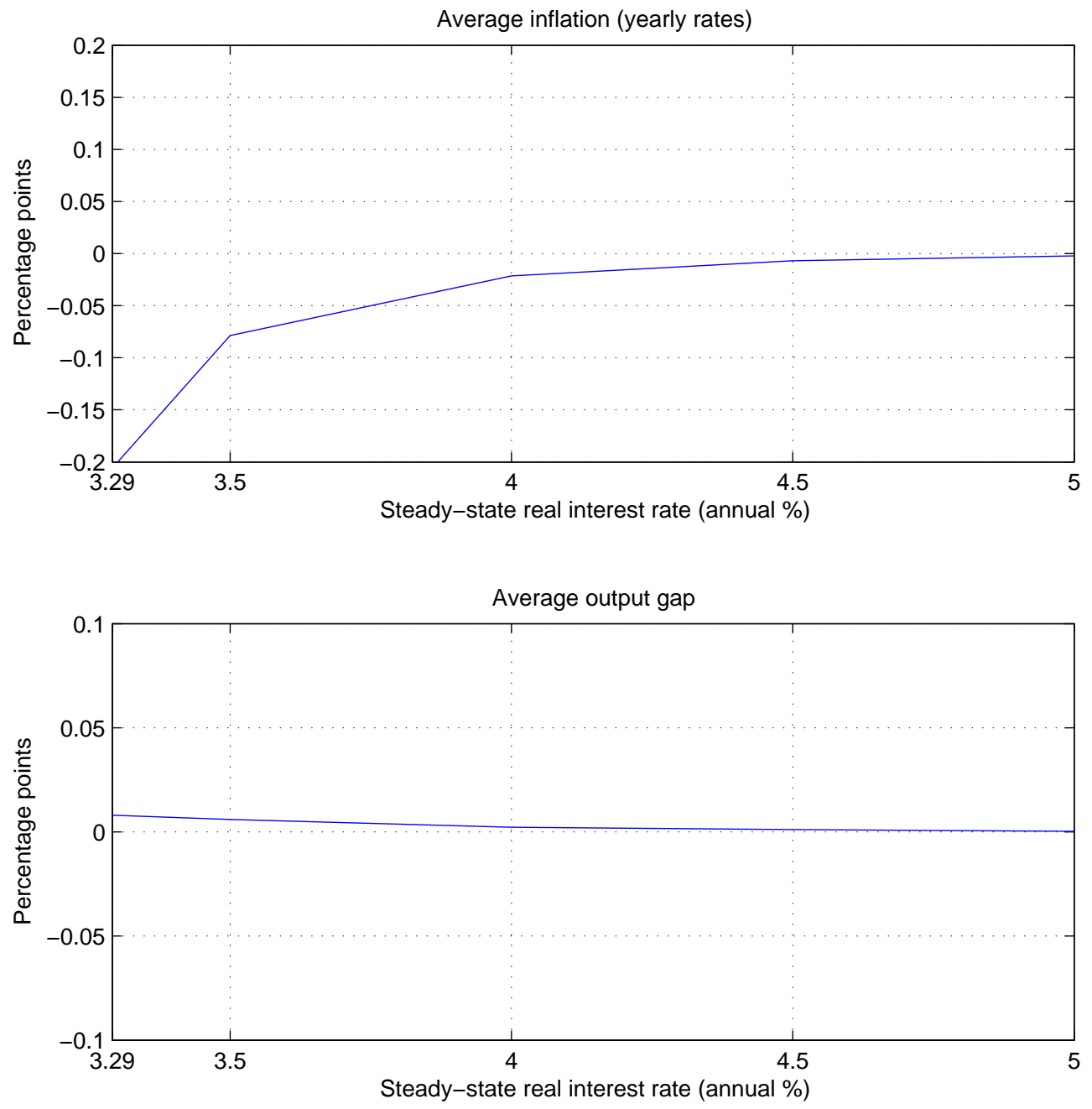

Figure 3: Average values (discretionary policy) 

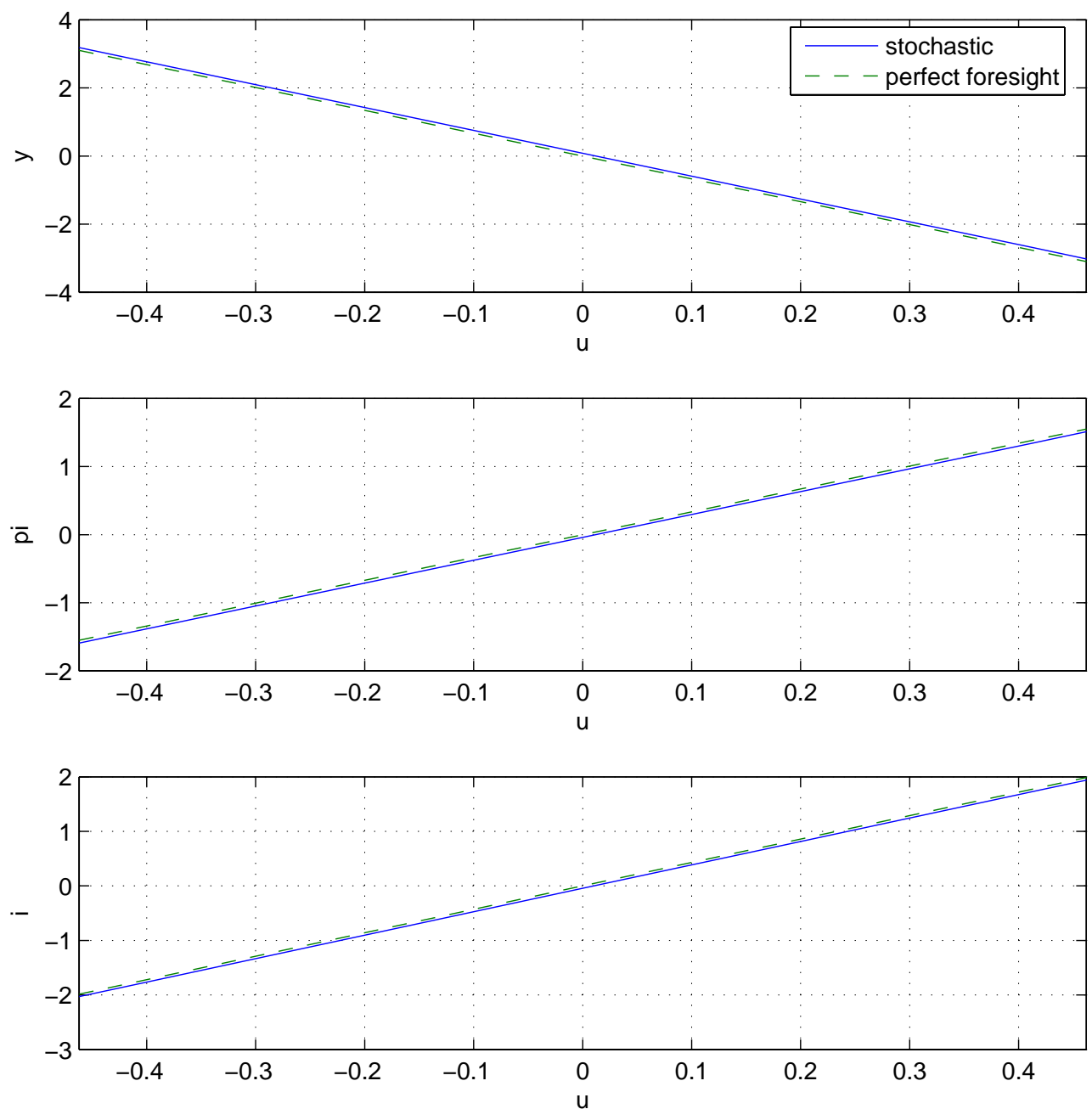

Figure 4: Equilibrium response to mark-up shocks (discretionary policy) 

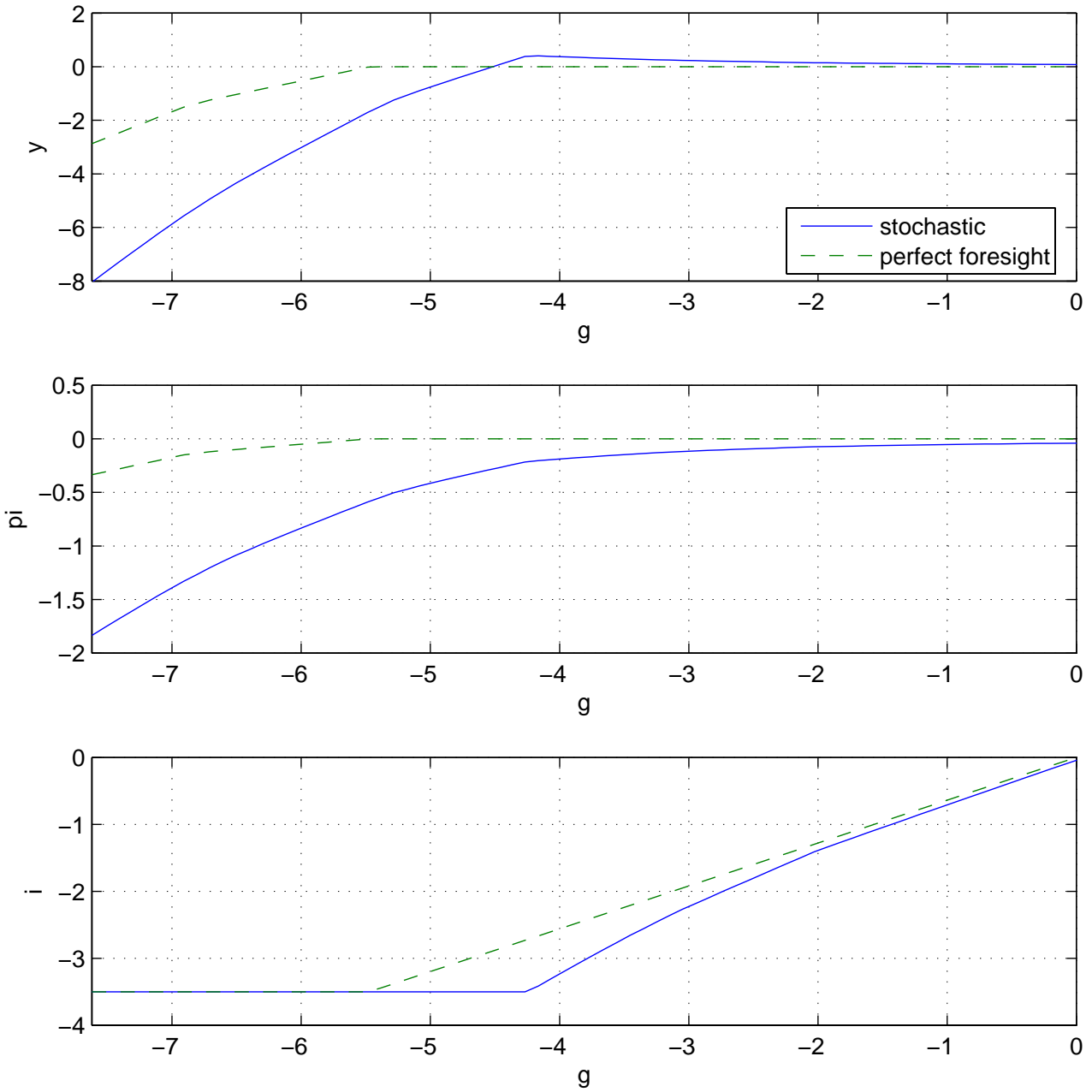

Figure 5: Equilibrium response to real-rate shocks (discretionary policy) 

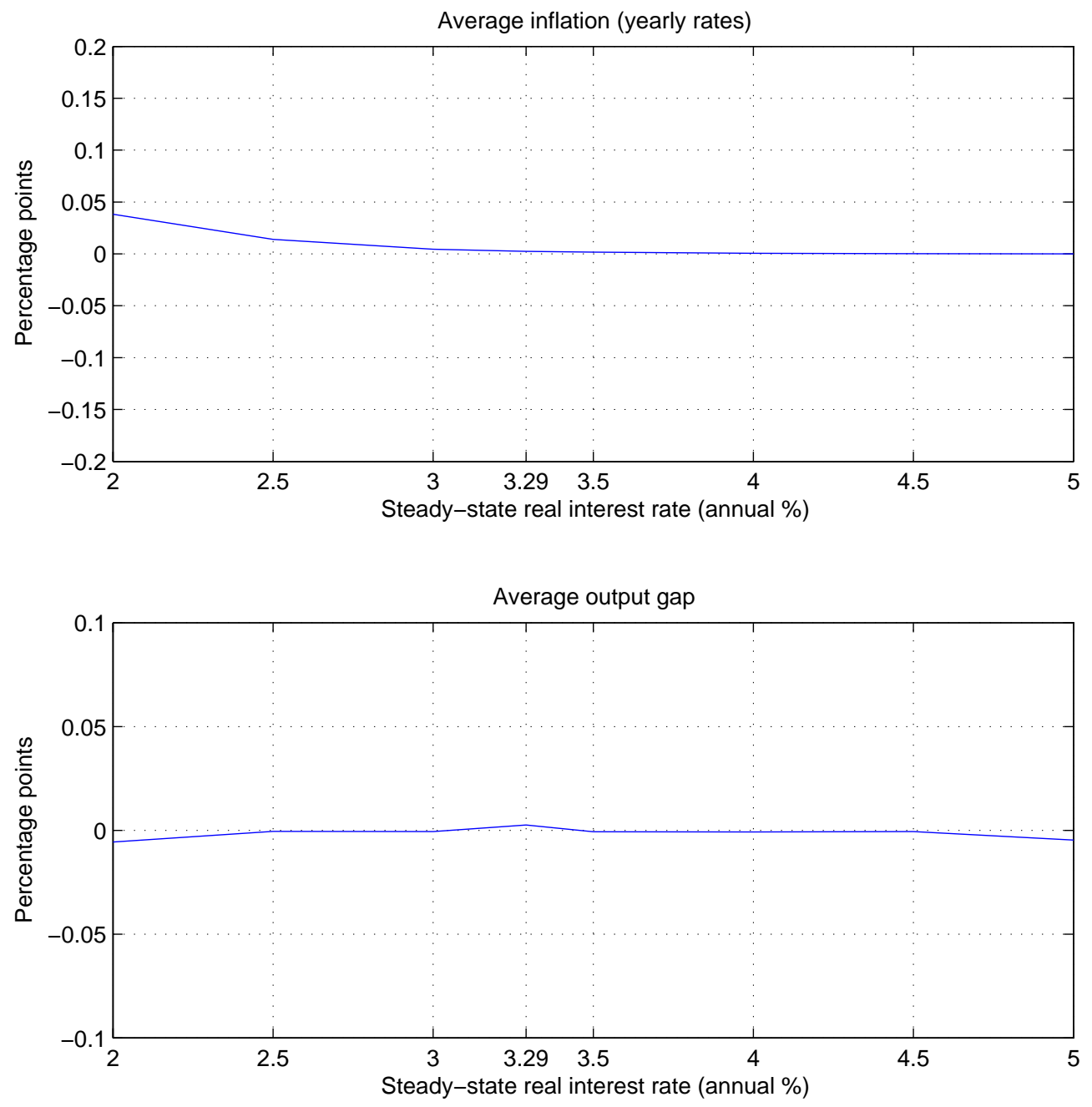

Figure 6: Average values (commitment policy) 

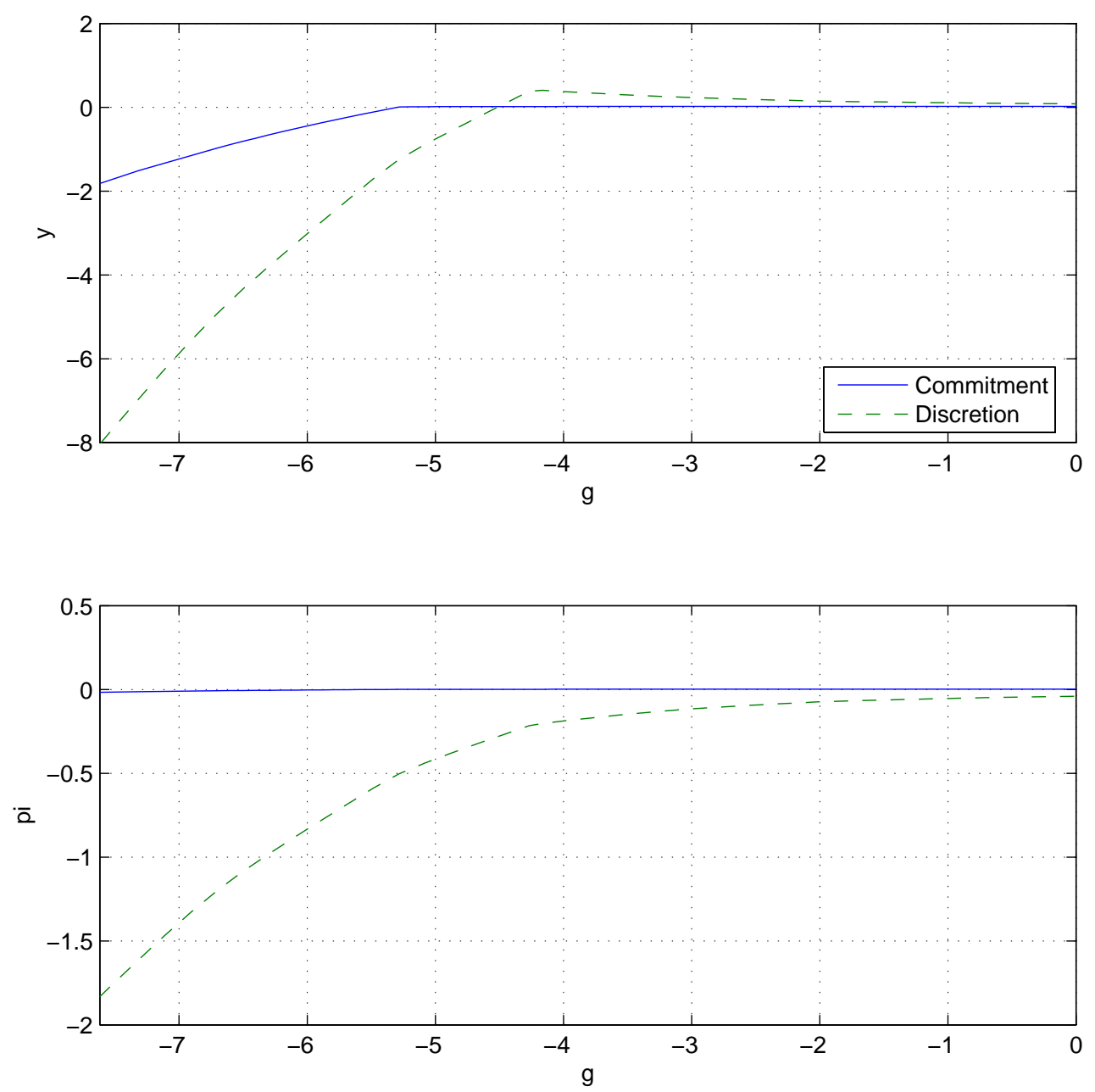

Figure 7: Equilibrium response to real rate shocks (commitment vs. discretionary policy) 


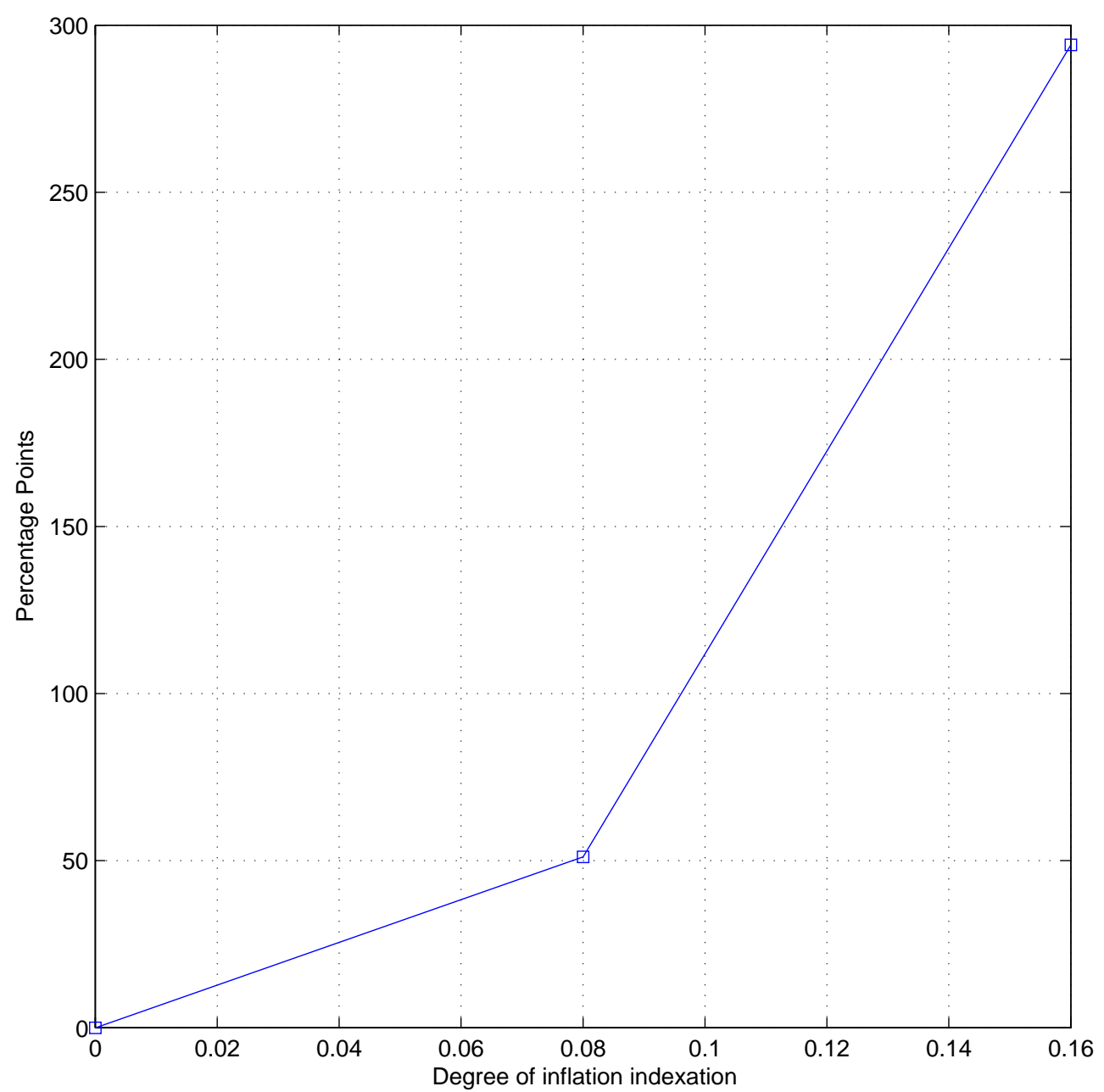

Figure 8: Increase in consumption losses from indexation to lagged inflation (discretionary policy) 

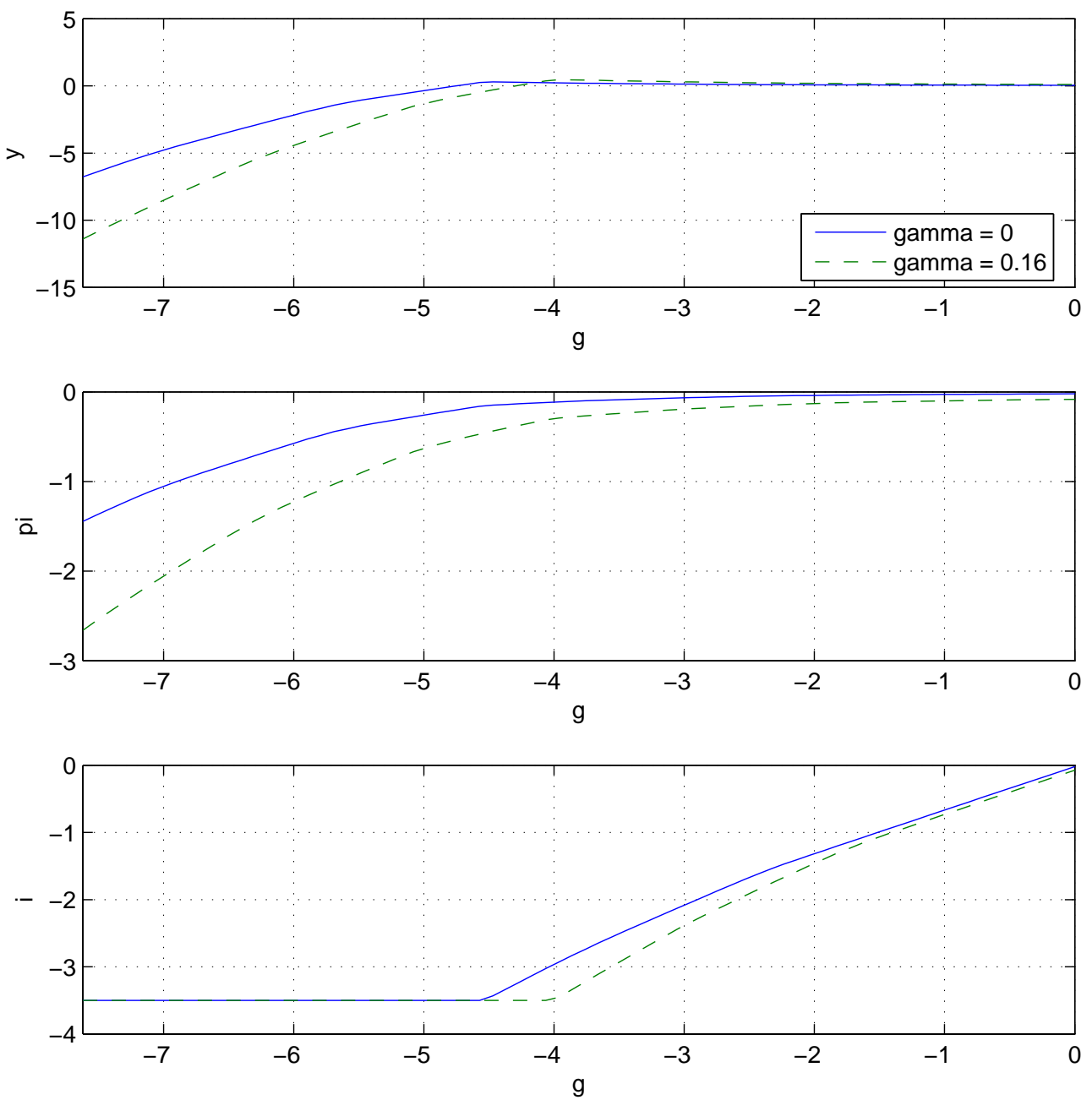

Figure 9: Equilibrium response to real rate shocks with indexation to lagged inflation (discretionary policy) 


\section{CFS Working Paper Series:}

\begin{tabular}{|c|c|c|}
\hline No. & Author(s) & Title \\
\hline $2005 / 07$ & $\begin{array}{l}\text { Dirk Krueger } \\
\text { Harald Uhlig }\end{array}$ & $\begin{array}{l}\text { Competitive Risk Sharing Contracts with One- } \\
\text { Sided Commitment }\end{array}$ \\
\hline $2005 / 08$ & $\begin{array}{l}\text { Torben G. Andersen } \\
\text { Tim Bollerslev } \\
\text { Peter F. Christoffersen } \\
\text { Francis X. Diebold }\end{array}$ & Volatility Forecasting \\
\hline $2005 / 09$ & $\begin{array}{l}\text { Markus Haas } \\
\text { Stefan Mittnik } \\
\text { Bruce Mizrach }\end{array}$ & $\begin{array}{l}\text { Assessing Central Bank Credibility During the } \\
\text { ERM Crises: Comparing Option and Spot Market- } \\
\text { Based Forecasts }\end{array}$ \\
\hline $2005 / 10$ & $\begin{array}{l}\text { Juan Carlo Conesa } \\
\text { Dirk Krueger }\end{array}$ & $\begin{array}{l}\text { On the Optimal Progressivity of the Income Tax } \\
\text { Code }\end{array}$ \\
\hline $2005 / 11$ & $\begin{array}{l}\text { Markus Haas } \\
\text { Stefan Mittnik } \\
\text { Marc S. Paolella }\end{array}$ & $\begin{array}{l}\text { Modeling and Predicting Market Risk With } \\
\text { Laplace-Gaussian Mixture Distributions }\end{array}$ \\
\hline $2005 / 12$ & $\begin{array}{l}\text { Dirk Krueger } \\
\text { Felix Kubler }\end{array}$ & $\begin{array}{l}\text { Pareto Improving Social Security Reform when } \\
\text { Financial Markets are Incomplete!? }\end{array}$ \\
\hline $2005 / 13$ & $\begin{array}{l}\text { Keith Kuester } \\
\text { VolkerWieland }\end{array}$ & $\begin{array}{l}\text { Insurance Policies for Monetary Policy in the Euro } \\
\text { Area }\end{array}$ \\
\hline $2005 / 14$ & $\begin{array}{l}\text { Berc Rustem } \\
\text { Volker Wieland } \\
\text { Stan Zakovic }\end{array}$ & $\begin{array}{l}\text { Stochastic Optimization and Worst-Case Analysis } \\
\text { in Monetary Policy Design }\end{array}$ \\
\hline $2005 / 15$ & $\begin{array}{l}\text { Dirk Krueger } \\
\text { Fabrizio Perri }\end{array}$ & $\begin{array}{l}\text { Does Income Inequality Lead to Consumption } \\
\text { Inequality?Evidence and Theory }\end{array}$ \\
\hline $2005 / 16$ & $\begin{array}{l}\text { Klaus Adam } \\
\text { Roberto Billi }\end{array}$ & $\begin{array}{l}\text { Discretionary Monetary Policy and the Zero Lower } \\
\text { Bound on Nominal Interest Rates }\end{array}$ \\
\hline
\end{tabular}

Copies of working papers can be downloaded at http://www.ifk-cfs.de 